\title{
ATRIBUTOS DE UM SOLO FLORESTAL EM UMA TOPOSSEQUÊNCIA E RELAÇÕES COM A COMUNIDADE ARBÓREA
}

\author{
Aurélio Lourenço Rodrigues ${ }^{1 *}$, Luciano Farinha Watzlawick ${ }^{2}$, Aline Marques Genú ${ }^{2}$, André Felipe Hess ${ }^{3}$, \\ Ângelo Augusto Ebling ${ }^{4}$ \\ ${ }^{1 *}$ Universidade Federal do Paraná, Programa de Pós-Graduação em Engenharia Florestal, Curitiba, Paraná, Brasil - \\ alourencorodrigues@gmail.com \\ ${ }^{2}$ Universidade Estadual do Centro Oeste, Departamento de Agronomia, Guarapuava, Paraná, Brasil - farinha@unicentro.br; \\ agenu@gmail.com \\ ${ }^{3}$ Universidade do Estado de Santa Catarina, Departamento de Engenharia Florestal, Lages, Santa Catarina, Brasil - hessandre@ yahoo.com.br \\ ${ }^{4}$ Universidade Federal Rural da Amazônia, Departamento de Engenharia Florestal, Parauapebas, Pará, Brasil - aebling@ @otmail.com \\ Recebido para publicação: 15/04/2014 - Aceito para publicação: 06/04/2016
}

\begin{abstract}
Resumo
O objetivo deste trabalho foi avaliar os atributos químicos e físicos de um solo florestal ao longo de uma topossequência, bem como a influência do solo sobre características estruturais e de diversidade da floresta. $\mathrm{O}$ estudo foi conduzido em um remanescente de Floresta Ombrófila Mista Aluvial no município de Guarapuava, $\mathrm{PR}$, onde foram instaladas três transecções (A, B e C) no sentido rio-bordadura, divididas em subunidades de $10 \times 10 \mathrm{~m}$. Em cada uma das 42 subunidades foram coletadas amostras para a caracterização química e granulométrica do solo (0,0-0,2 m) e efetuada a análise da Resistência à Penetração (RP). Realizou-se análise de agrupamentos (método de ligação completa) para identificar a similaridade das subunidades em relação aos atributos do solo e da vegetação. Uma análise de componentes principais foi efetuada para avaliar as intercorrelações entre as variáveis edáficas e de vegetação e identificar as variáveis de maior expressão na área de estudo. Os resultados indicaram solos com baixa saturação por bases, acidez elevada e alta concentração de $\mathrm{Al}$ especialmente nas unidades mais afastadas do rio. Identificou-se um gradiente edáfico nas transecções $\mathrm{B}$ e C, com reflexos sobre a estrutura e diversidade da vegetação. Das variáveis edáficas consideradas, o pH foi a mais determinante, exercendo influências sobre os demais atributos do solo e sobre a vegetação.

Palavras-chave: Floresta aluvial; química do solo; análise de agrupamentos; análise de componentes principais.
\end{abstract}

\begin{abstract}
Properties of a forest soil along a topossequence and its relationships with the arboreal community. The purpose of this study was to evaluate the chemical and physical properties of a forest soil along a topossequence, as well as the influence of the soil on structural and diversity characteristics of vegetation. The study was conducted in a remnant of Alluvial Araucaria Forest in Guarapuava, PR, where three transects (A, B and C) were installed towards the river-boundary direction, divided into subunits of $10 \times 10 \mathrm{~m}$. In each subunit samples were collected for chemical and particle size characterization of soil $(0.0-0.2 \mathrm{~m})$ and performed the analysis of Penetration Resistance (PR). We conducted cluster analysis to identify the similarity of the subunits in relation to soil properties and vegetation. A principal component analysis was performed to evaluate the interrelations between soil variables and vegetation and to identify the variables with the highest expression. The results indicated soils with low base saturation, high acidity and high concentration of Al. A soil gradient were identified in transects B and C, with reflections on the structure and diversity of vegetation. Of soil variables considered, the $\mathrm{pH}$ was the most decisive, exerting influence on other soil and on vegetation characteristics.

Keywords: Alluvial forest; soil chemistry; multivariate analysis.
\end{abstract}

\section{INTRODUÇÃO}

Os padrões da vegetação são invariavelmente influenciados pelas diferenças no ambiente. De modo especial, as variações do relevo impõem restrições ambientais sobre o desenvolvimento da vegetação ao produzir substratos complexos e com estrutura, condições químicas e hídricas diferenciadas (LOPES et al., 2016). Enquanto o clima é considerado como o principal fator responsável pelo controle da distribuição de organismos e comunidades em larga escala, a importância de características específicas de cada habitat, em especial as condições do solo, assume especial importância em escalas locais (McGILL, 2010). Portanto, compreender as 
relações entre a vegetação e condições ambientais é fundamental para estudos ecológicos e para a conservação da biodiversidade (ZELLWEGER et al., 2015; MICHAELIS et al., 2016).

Os solos são um importante constituinte dos ecossistemas terrestres, incluindo os ecossistemas florestais. A sua produtividade está ligada a atributos específicos, como a capacidade de favorecer o crescimento radicular, a capacidade de retenção e suprimento de água, a capacidade de adsorção, o suprimento e ciclagem de nutrientes minerais, a promoção de trocas gasosas, a atividade biológica, a fixação e liberação de carbono (ROUSSEAU et al., 2012).

A diversidade de espécies e estrutura complexa das florestas tropicais e subtropicais remetem à ideia de que essas ocupam solos bastante férteis (HEINEMAN et al., 2016). No entanto, atualmente é reconhecido que os solos desses ecossistemas são de baixa fertilidade (JOHN et al., 2007), o que pode ser atribuído às altas taxas de precipitação e temperaturas, catalisadores do intemperismo, a que estão sujeitas tais regiões.

O estado nutricional das plantas é controlado pela sua capacidade de absorção de nutrientes (dependente da sua constituição genética), disponibilidade dos nutrientes no solo e outros fatores ambientais, como a disponibilidade hídrica (PALARDY, 2008). Em florestas tropicais e subtropicais, a alta diversidade de espécies, variabilidade de solos existentes, condições distintas de relevo e interações com o clima afetam a nutrição mineral das árvores (JOHN et al., 2007). Tais interações são complexas e específicas em cada sítio, o que provavelmente é um dos fatores que explicam a razão desse assunto ser tão pouco compreendido nesses ecossistemas. Portanto, informações a respeito das exigências nutricionais das árvores em florestas naturais, bem como das características dos solos nesses ecossistemas são necessárias para compreender as respostas dos ambientes aos distúrbios naturais e antropogênicos.

O objetivo deste trabalho foi avaliar a influência de um gradiente topográfico sobre as condições químicas e físicas do solo e sua relação com características estruturais e de diversidade da comunidade arbórea em um remanescente urbano de Floresta Ombrófila Mista Aluvial.

\section{MATERIAL E MÉTODOS}

A área de estudo compreende um fragmento de Floresta Ombrófila Mista Aluvial, localizado no município de Guarapuava, PR, nas dependências da Universidade Estadual do Centro Oeste (UNICENTRO) (coordenadas: $25,38^{\circ}$ Sul e $51,49^{\circ}$ Oeste). Em razão da proximidade do fragmento com áreas urbanizadas, o mesmo esteve sujeito a intervenções antrópicas no passado, como corte seletivo de espécies e pastoreio. Entretanto, o fragmento foi isolado há mais de 20 anos, sem apresentar distúrbios significativos de ordem antropogênica nesse período. O remanescente florestal situa-se a uma altitude média de $1000 \mathrm{~m}$, sob clima mesotérmico úmido com verões amenos, tipo Cfb, conforme Köppen (1948). As classes de solos na área variam de solos mais profundos e estruturados como os Latossolos Bruno a solos hidromórficos de influência aluvial, nas proximidades do rio Cascavelzinho.

Foram instaladas ao longo de uma topossequência três transecções, denominadas A, B e C, com largura padrão de 10 m e comprimento de 150 m, 130 m e 140 m, respectivamente, conforme distância do rio até a borda da floresta. Todas as transecções foram divididas em subunidades de $10 \times 10 \mathrm{~m}$. Em cada subunidade foram realizadas três coletas de solo na profundidade de $0-20 \mathrm{~cm}$ com trado holandês. As amostras foram misturadas, formando uma amostra composta por subunidade. As amostras foram submetidas à análise laboratorial para determinação do pH (em $\mathrm{CaCl}_{2}$ ), Matéria Orgânica, Fósforo (P - solução de Mehlich), Potássio (K), Cálcio (Ca), Magnésio (Mg), Alumínio ( $\mathrm{Al})$, Hidrogênio e Alumínio ( $\mathrm{H}+\mathrm{Al})$ e análise granulométrica (método da pipeta), conforme metodologia da Empresa Brasileira de Pesquisa Agropecuária (EMBRAPA) (1997).

Em cada subunidade foram efetuadas cinco avaliações da resistência à penetração, na profundidade de 0-60 cm, com a utilização de Medidor Eletrônico de Compactação do Solo (PenetroLOG 1020, Falker). Os cinco pontos foram distribuídos aleatoriamente nas subunidades e medidas da resistência à penetração foram tomadas com resolução de $5 \mathrm{~cm}$ em cada ponto (12 medidas por ponto). Calculou-se a média aritmética das medições de 5-60 cm para cada ponto e a partir das médias dos cinco pontos de cada subunidade, obteve-se a média da resistência à penetração por subunidade. A definição do grau de compactação foi feita conforme classificação do United States Department of Agriculture (USDA, 1993). Adicionalmente, visando identificar a influência do nível do rio sobre as subunidades adjacentes, uma análise visual foi efetuada sobre o terreno, visando identificar pontos recorrentes de inundação.

Avaliou-se a similaridade entre as subunidades das transeções por meio de análise de agrupamentos com base nos atributos do solo e atributos da vegetação obtidos para cada subunidade. Os atributos da vegetação considerados foram: área basal total da subunidade (G) e o índice de Diversidade de Shannon (H'), também de cada subunidade. A vegetação nas transeções foi inventariada considerando todos os indivíduos com Diâmetro à Altura do Peito (DAP) maior ou igual a $5 \mathrm{~cm}$. A identificação botânica das espécies foi feita com base no APG 
III (2009). O Software STATGRAPHICS XV foi empregado na análise de agrupamento, utilizando-se o método da ligação completa.

A análise dos componentes principais (PCA) foi aplicada sobre as variáveis do solo, $\mathrm{G}$, densidade $(\mathrm{N})$ e diversidade (representada pelo H' de cada subunidade), visando identificar as inter-correlações entre estas variáveis e identificação daquelas de maior peso na representação da floresta em estudo. A análise dos componentes principais foi realizada com o auxílio do software STATISTICA 10.

Para fins de comparação gráfica entre os teores dos elementos e variáveis da vegetação, que apresentam unidades diferenciadas, os mesmos foram padronizados com valores variando de 0 a 1 , considerando as três transecções. Sendo assim, o maior valor absoluto de determinada variável em uma subunidade assumiu o valor 1 , enquanto seu menor valor e outra subunidade assumiu valor zero, enquanto os demais valores assumiram número proporcional entre 0 e 1 .

\section{RESULTADOS E DISCUSSÃO}

\section{Caracterização química e granulométrica do solo florestal}

Os resultados das análises de solo estão representados pelas médias aritméticas das subunidades de cada transecções e encontram-se relacionados na tabela 1. De modo geral, as características dos solos da área avaliada indicam elevada acidez, baixa disponibilidade de nutrientes, alta concentração de Al trocável e baixa saturação por bases, representando solos naturalmente de baixa fertilidade, com base em Mello et al., 1983.

Tabela 1. Média aritmética dos atributos químicos e físicos do solo $(0-20 \mathrm{~cm})$ em três transecções em um remanescente de Floresta Ombrófila Mista Aluvial em Guarapuava, PR.

Table 1. Arithmetic mean of chemical and physical properties of soil $(0-20 \mathrm{~cm})$ along 3 transections in a Alluvial Araucaria Forest in Guarapuava, PR.

\begin{tabular}{|c|c|c|c|c|}
\hline \multirow{2}{*}{ Atributo } & \multirow{2}{*}{ Unidade } & \multicolumn{3}{|c|}{ Transecção } \\
\hline & & A & $\mathrm{B}$ & C \\
\hline $\mathrm{pH}$ & & 4,00 & 4,30 & 4,30 \\
\hline MO & g.dm ${ }^{-3}$ & 51,80 & 59,60 & 55,90 \\
\hline $\mathrm{P}$ & mg.dm ${ }^{-3}$ & 1,30 & 3,00 & 3,10 \\
\hline K & cmol.dm ${ }^{-3}$ & 0,09 & 0,06 & 0,10 \\
\hline $\mathrm{Ca}$ & cmol. $\mathrm{dm}^{-3}$ & 0,80 & 2,50 & 2,60 \\
\hline $\mathrm{Mg}$ & cmol.dm ${ }^{-3}$ & 0,80 & 1,61 & 1,50 \\
\hline $\mathrm{Al}$ & cmol. dm ${ }^{-3}$ & 2,70 & 1,60 & 1,40 \\
\hline $\mathrm{H}+\mathrm{Al}$ & cmol. $\mathrm{dm}^{-3}$ & 12,00 & 9,10 & 9,60 \\
\hline SB & cmol.dm ${ }^{-3}$ & 1,60 & 4,10 & 4,10 \\
\hline CTC & $\mathrm{cmol} \cdot \mathrm{dm}^{-3}$ & 13,60 & 13,20 & 13,80 \\
\hline V & $\%$ & 11,80 & 31,40 & 30,40 \\
\hline $\mathrm{m}$ & $\%$ & 62,80 & 35,00 & 31,10 \\
\hline Areia & g. $\mathrm{kg}^{-1}$ & 208,70 & 193,90 & 195,00 \\
\hline Silte & g. $\mathrm{kg}^{-1}$ & 292,00 & 280,00 & 257,90 \\
\hline Argila & g. $\mathrm{kg}^{-1}$ & 499,30 & 526,20 & 547,10 \\
\hline $\mathrm{RP}$ & $\mathrm{MPa}$ & 0,805 & 0,630 & 0,658 \\
\hline
\end{tabular}

em que: $\mathrm{pH}=$ potencial hidrogeniônico $\left(\mathrm{em} \mathrm{CaCl}_{2}\right) ; \mathrm{MO}=$ Matéria Orgânica; $\mathrm{P}=$ Fósforo ( solução de Mehlich); $\mathrm{K}=\mathrm{Potá}$ ssio; Ca = Cálcio; $\mathrm{Mg}=$ Magnésio $; \mathrm{Al}=$ Alumínio $\mathrm{H}=$ Hidrogênio; $\mathrm{Al}=$ Alumínio; $\mathrm{SB}=$ Soma de bases $; \mathrm{CTC}=$ Capacidade de troca catiônica; $\mathrm{V}=\mathrm{Saturação}$ por bases; $\mathrm{m}=$ Saturação por Alumínio; $\mathrm{RP}=$ resistência à penetração.

A análise granulométrica demonstrou a predominância da fração argila nos solos da área de estudo (Tabela 1). Em todas as subunidades de todas as transecções a classe textural predominante, segundo classificação da EMBRAPA (1997), foi a Argilosa. Quanto à compactação dos solos, representada pela resistência à penetração, conforme a tabela 1 , foram classificados na classe intermediária baixa $(0,1$ a $1 \mathrm{MPa})$, indicando pouca ou nenhuma restrição ao desenvolvimento radicular das plantas nestas áreas, conforme orientação da USDA (1993).

O baixo grau de compactação obtido para os solos do remanescente florestal está relacionado ao isolamento da área, que não conta com intervenções antrópicas significativas ou pisoteio por animais domésticos. A compactação dos solos está relacionada ao aumento de sua densidade, redução da porosidade e alterações na distribuição, geometria, morfologia e conectividade dos poros (CAMBI et al., 2015). A compactação, quando presente, leva à redução na condutividade hidráulica dos solos e menor aeração das raízes, proporcionando menor crescimento vegetal (VENANZI et al. 2016). Portanto, a ausência de compactação

FLORESTA, Curitiba, PR, v. 46, n. 2, p. 145 - 154, abr. / jun. 2016

Rodrigues, A. L. et al.

ISSN eletrônico 1982-4688

DOI: $10.5380 /$ rf.v46i2.36219 
expressiva na área de estudo indica solos com características físicas apropriadas ao bom desenvolvimento da comunidade vegetal.

\section{Similaridade das unidades amostrais}

As unidades agruparam-se, predominantemente, de acordo com a transecção, representadas pelas letras, e/ou de acordo com o gradiente edáfico, representado pelos números (Figura 1). Após traçar a linha "fenon" na metade da distância euclidiana máxima, obteve-se a formação de quatro agrupamentos.

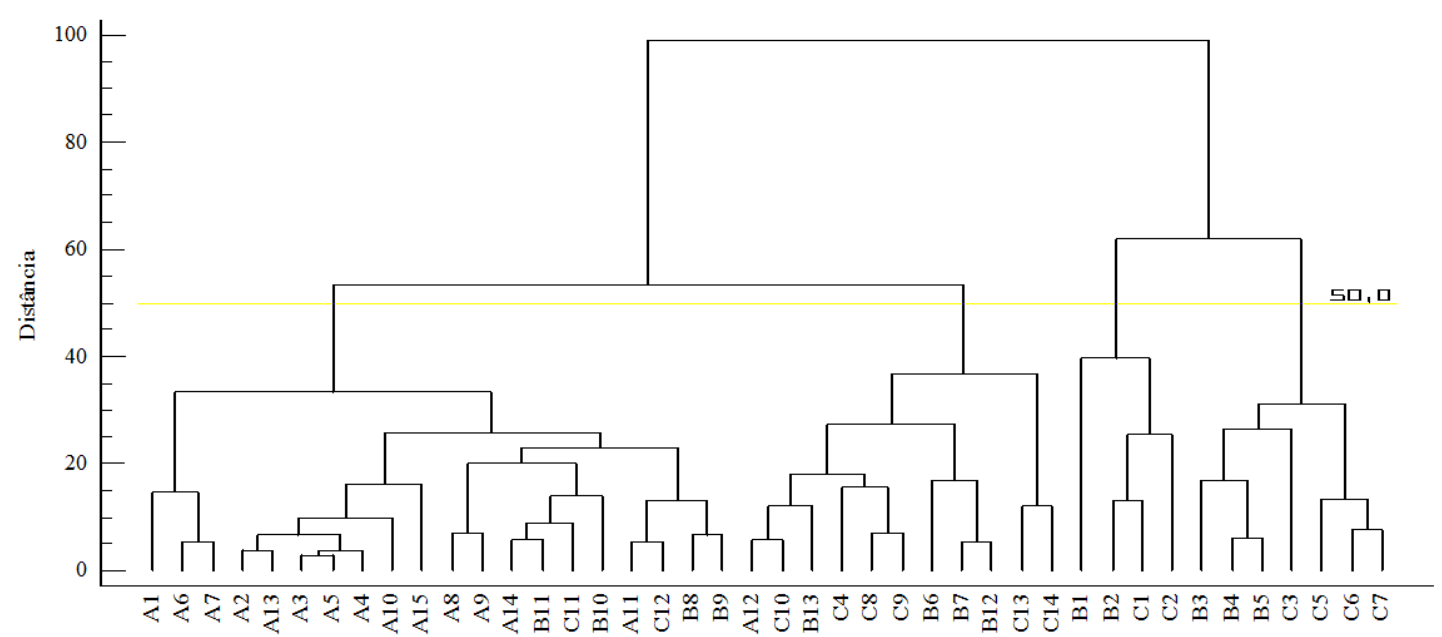

Figura 1. Similaridade conforme distância euclidiana quadrada, pelo método de ligação completa entre as subparcelas de cada transecção, de acordo com características edáficas e da vegetação, em um fragmento de Floresta Ombrófila Mista Aluvial, Guarapuava, PR.

Figure 1. Similarity according to the squared euclidean distance, by the method of complete linkage among the subplots of each transection in relation to the edaphic and vegetation properties, in a Alluvial Araucária Forest fragment, Guarapuava, PR.

O primeiro agrupamento formado com a divisão pela linha fenon (à esquerda), concentrou 14 das 15 parcelas da transecção A. Observa-se que esta transecção apresentou maior homogeneidade quanto às condições edáficas e de vegetação, distinguindo-se consideravelmente das demais. Embora o primeiro agrupamento tenha sido formado principalmente pelas subunidades da transecção A, nota-se que a ordem de associação entre as parcelas não seguiu um padrão de similaridade do maior número para o menor, ou vice-versa, indicando a inexistência de um gradiente edáfico e vegetacional marcante ao longo dessa.

A formação do segundo agrupamento envolveu subunidades de todas as transecções, porém com destaque para a transecção C, representada por seis de suas 14 subunidades. Observa-se nesse grupo dois tipos distintos de associação. O primeiro indica a tendência de associação das subunidades finais das transecções B e $\mathrm{C}$ (representadas pelos números de 10 a 14); enquanto o segundo envolve parcelas nas alturas médias também das transecções $\mathrm{B}$ e $\mathrm{C}$ (representadas pelos números de 4 a 9).Considerando o terceiro agrupamento formado, esse agrupou o menor número de subunidades (4), e concentrou as parcelas iniciais das transecções B e C. Finalmente, o quarto agrupamento formado, também demonstrou a associação das parcelas na altura média das transecções B e C.

O segundo, terceiro e quarto agrupamentos indicam a existência de um gradiente edáfico e vegetacional nas transecções B e C, enquanto a grande predominância das subunidades da transecção A no primeiro grupo indica maior homogeneidade dessa área, que a diferencia das demais transecções. Os resultados apontam para existência de solos com características distintas na área amostrada pela transecção A, trazendo reflexos significativos sobre a composição florística local, visto que a média do Indice de Shannon para esta transecção foi estatisticamente superior às demais $(\mathrm{A}=1,66, \mathrm{~B}=1,01 \mathrm{e} \mathrm{C}=1,16)$, conforme teste de Tukey a $95 \%$ de probabilidade. As diferenças encontradas entre estas áreas devem-se principalmente ao grau de influência do rio subjacente e inundações periódicas. Enquanto as transecções B e C têm suas subunidades iniciais diretamente afetadas pelos processos hidrológicos do rio e inclinação de 4,6\% e 4,2\%, a transecção A não apresenta influência direta dos deflúvios e a variação da declividade ao longo de seu comprimento é menor $(1,3 \%)$, apresentando, portanto, maior homogeneidade quanto às características edáficas. 
A maior proximidade ao rio e relevo mais plano das parcelas iniciais das transecções $\mathrm{B}$ e $\mathrm{C}$ favoreceram a formação de solos aluviais nestas áreas. Conforme Boettinger (2005), a gênese de tais solos está ligada à deposição de materiais transportados pelos corpos d'água, que conferem ao solo originário diferentes composições e textura, que dependem do material de origem e das características do ambiente em que o solo é formado. Esta deposição contínua de sedimentos pode ser responsável pelos maiores teores de nutrientes observados nestas parcelas, quando comparadas às subunidades adjacentes e toda a transecção A, que não contam com influência direta dos deflúvios.

Além dos aspectos relacionados à deposição de sedimentos, a concentração maior de nutrientes nas parcelas iniciais das transecções B e C pode ser resultado da drenagem deficiente observada nesses locais, que reduz as perdas de bases pelo processo de lixiviação e retarda a decomposição da matéria orgânica (MONTAGNE et al., 2009). Observa-se, na figura 2, a tendência apresentada pelos teores de P, K, Ca e Mg nas transecções B e C, demonstrando a existência de um gradiente edáfico, com redução nos teores de macronutrientes do solo à medida que as subunidades se afastam da zona de deposição de deflúvios e de drenagem deficiente.
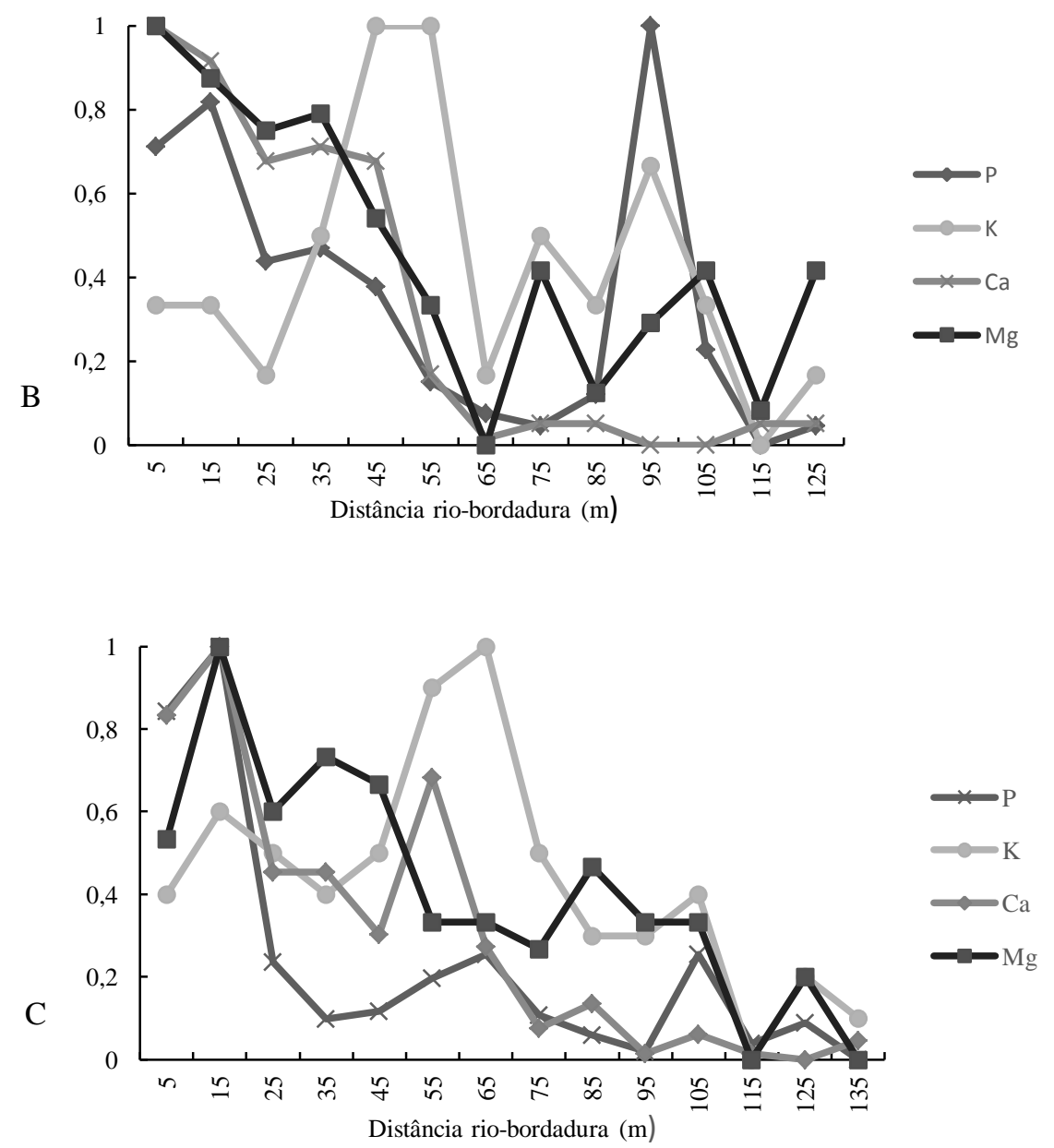

Figura 2. Teores de macronutrientes ao longo de uma topossequência nas transecções B e C em um fragmento de Floresta Ombrófila Mista Aluvial, Guarapuava, PR (Por motivo de comparação em uma mesma escala, variáveis com diferentes unidades tiveram seus valores relativizados de 0-1).

Figure 2. Macronutrients content along an edaphic gradient in transections B and C, in a Alluvial Araucaria Forest, Guarapuava, PR (Aiming the comparison on a same scale, variables with different units had their values relativized $0-1)$.

Comportamento inverso foi observado para o $\mathrm{pH}$, que diminuiu à medida que as subunidades afastavam-se da zona de deflúvio, assim como também houve aumento do Al trocável. O pH nas subunidades finais das transecções B e C (mais afastadas do rio) atingiu níveis críticos, variando entre 3,9 e 4,0, valores

FLORESTA, Curitiba, PR, v. 46, n. 2, p. 145 - 154, abr. / jun. 2016

Rodrigues, A. L. et al.

ISSN eletrônico 1982-4688

DOI: $10.5380 /$ rf.v46i2.36219 
considerados muito baixos (MELLO et al., 1983). O solo da transecção A também foi considerado muito ácido como um todo, variando de 3,9 a 4,2. Por outro lado, as subunidades iniciais das transecções B e C (mais próximas ao rio) apresentaram $\mathrm{pH}$ mais elevado, variando de 4,6 a 5,0 nas cinco primeiras subunidades de $\mathrm{B}$, e de 4,2 a 5,2 nas respectivas subunidades de C.

Em condições de elevada acidez, como é o caso de grande parte das subunidades em todas as transecções, os compostos de alumínio, ferro e manganês tornam-se bastante solúveis, e além de causarem toxidez às plantas, são responsáveis pela fixação de fósforo e pela formação de compostos de fósforo insolúveis na solução do solo, reduzindo significativamente a disponibilidade desse nutriente às plantas. Semelhantemente, o hidrogênio desloca o cálcio e o magnésio dos colóides do solo, que uma vez estando na solução do solo em formas solúveis, podem ser perdidos por lixiviação (COELHO; VERLENGIA, 1973). Tais fatores explicam o aumento na disponibilidade de Al trocável e redução na disponibilidade dos macronutrientes nas subunidades avaliadas, à medida que o $\mathrm{pH}$ diminui.

Os teores de matéria orgânica no solo variaram de 29,6 g.dm ${ }^{-3}$ a 67,1 g.dm $(2,7 \%$ e $6,7 \%$, respectivamente) considerando as três transecções. Tais teores são considerados de alto a muito alto (COELHO; VERLENGIA, 1973). Os níveis de matéria orgânica observados nos solos em estudo podem se constituir em um agravante para a questão da acidez. A acidificação decorrente desse fator ocorre pelo fato de que a matéria orgânica, rica em ácidos orgânicos e fenóis, fornece prótons de $\mathrm{H}^{+}$que tendem a acidificar os solos. No entanto, essa acidificação aparece de modo acentuado na acidez potencial, enquanto a variação na acidez ativa é menor, podendo até em alguns casos não se observar correlação entre a matéria orgânica e o pH do solo (MELLO et al., 1983).

A correlação linear entre as variáveis matéria orgânica e pH apresentou um relacionamento negativo e significativo $(r=-0,325 ; \mathrm{p}<0,05)$. Esta correlação, embora fraca, indica a importância da matéria orgânica como fonte de acidez para os solos em questão.

\section{Análise dos Componentes Principais}

As variáveis edáficas e da vegetação submetidas à análise dos componentes principais resultou nos autovalores e porcentagem de variância conforme tabela 2. Considerando o valor mínimo dos autovalores para a formação dos componentes principais $\geq 1$, houve a formação de quatro componentes, que juntos explicam $71,6 \%$ da variância.

Tabela 2. Autovalores e variância dos componentes principais resultantes das variáveis edáficas e da vegetação de um fragmento de Floresta Ombrófila Mista Aluvial, Guarapuava, PR.

Table 2. Eigenvalues and variance of the principal components resulted of the edaphic and vegetation variables from an Alluvial Araucaria Forest, Guarapuava, PR.

\begin{tabular}{|c|c|c|c|c|}
\hline \multirow{2}{*}{ Variáveis } & \multicolumn{4}{|c|}{ Componentes } \\
\hline & 1 & 2 & 3 & 4 \\
\hline $\mathrm{pH}$ & $-0,94$ & 0,14 & 0,03 & 0,16 \\
\hline MO & 0,29 & $-0,30$ & 0,06 & $-\mathbf{0 , 5 7}$ \\
\hline $\mathrm{P}$ & $-0,76$ & 0,10 & 0,24 & 0,28 \\
\hline $\mathrm{K}$ & $-0,08$ & 0,37 & $\mathbf{0 , 5 9}$ & $-0,26$ \\
\hline $\mathrm{Ca}$ & $-0,94$ & 0,09 & 0,17 & 0,10 \\
\hline $\mathrm{Mg}$ & $-0,84$ & $-0,19$ & 0,16 & $-0,21$ \\
\hline $\mathrm{Al}$ & 0,93 & $-0,05$ & 0,00 & 0,06 \\
\hline CTC & 0,11 & $-0,30$ & 0,71 & $-0,17$ \\
\hline Areia & 0,12 & $\mathbf{0 , 7 0}$ & 0,3 & 0,10 \\
\hline Silte & 0,49 & $\mathbf{0 , 5 9}$ & $-0,19$ & $-0,09$ \\
\hline Argila & $-0,43$ & $-0,85$ & $-0,04$ & 0,01 \\
\hline $\mathrm{RP}$ & 0,67 & $-0,11$ & 0,05 & $-0,09$ \\
\hline G & $-0,67$ & 0,22 & $-0,18$ & $-0,35$ \\
\hline $\mathrm{Ni}$ & $-0,52$ & 0,29 & $-0,27$ & $-0,61$ \\
\hline $\mathrm{H}^{\prime}$ & 0,78 & $-0,04$ & 0,26 & $-0,09$ \\
\hline Autovalor & 6,24 & 2,11 & 1,27 & 1,11 \\
\hline Variância (\%) & 41,63 & 14,04 & 8,48 & 7,45 \\
\hline Variância Acum. (\%) & 41,63 & 55,66 & 64,15 & 71,6 \\
\hline
\end{tabular}

RP: Resistência à penetração; G: Área Basal; Ni: Número de indivíduos; H': Índice de Diversidade de Shannon 
O primeiro componente ou fator apresentou o autovalor expressivo de 6,24, representando 41,63\% da variância total. O segundo componente mais representativo, com autovalor de 2,11, correspondeu a 14,04\% do total da variância. O terceiro e quarto componentes apresentaram autovalores iguais a 1,27 e 1,11, sendo responsáveis por $8,48 \%$ e $7,45 \%$ da variância dos dados, respectivamente.

As variáveis mais representativas do componente 1 foram o $\mathrm{pH}$, juntamente com o $\mathrm{Ca}$ e $\mathrm{Al}$. Considerando que esse foi o componente mais expressivo na análise, pode-se afirmar que das variáveis consideradas, o pH, Ca e $\mathrm{Al}$ são as mais determinantes, possuindo altas correlações com a maioria das demais variáveis, sejam edáficas ou da vegetação. A importância destas duas variáveis pode ser avaliada com base no alto valor da correlação com o fator $1(-0,94)$, resultado de uma relação inversa com o componente.

Observa-se que o fator 1 representa bem as condições químicas e de fertilidade do solo, agregando além do $\mathrm{pH}$ os nutrientes $\mathrm{Ca}, \mathrm{Mg}$ e $\mathrm{P}$, além do $\mathrm{Al}$ trocável, e a variável física do solo - resistência à penetração. Juntamente com essas variáveis edáficas, duas variáveis da vegetação (Área Basal - G e Índice de Diversidade de Shannon - H') foram adicionadas ao componente 1, indicando estreita relação entre as condições químicas, de fertilidade e compactação do solo com a comunidade arbórea.

O segundo componente foi composto exclusivamente pelas variáveis físicas do solo, como teores das frações areia, silte e argila. Obteve-se correlação negativa forte entre a argila e as demais frações. Considerando que a classe textural predominante nos solos de todas as subunidades foi a Argilosa, a relação inversa entre a argila e as demais frações ocorre à medida que os teores de argila são maiores no solo, em detrimento das frações silte e areia, enquanto maiores teores de areia + silte promovem, consequentemente, a redução nos teores de argila. $\mathrm{O}$ autovalor obtido por esse componente indica a importância das frações na explicação da variância total das características do solo.

O terceiro componente agrupou as variáveis CTC e K, enquanto o quarto componente foi representado pela Matéria Orgânica (MO) e número de indivíduos arbóreos (Ni). A CTC, originária da superfície de troca dos colóides do solo, representa a quantidade total de cátions retidos à superfície desses materiais em condição permutável. Em condições de baixa e média CTC, como é o caso dos solos de todas as subunidades, há adsorção preferencial de cátions monovalentes às cargas negativas dos colóides do solo, como o $\mathrm{K}$, enquanto altas CTC adsorvem melhor cátions bivalentes, como o Ca e o Mg (MELLO et al., 1983). Sendo assim, esta característica pode estar relacionada à correlação estabelecida entre a CTC e o K nos solos em questão.

Destaca-se no componente 1, a concentração das variáveis químicas do solo e a relação inversa especialmente entre o $\mathrm{pH}, \mathrm{Ca}, \mathrm{Mg}$ e $\mathrm{P}$ e as variáveis pertencentes ao mesmo fator porém positivamente correlacionadas, como o Índice de Diversidade de Shannon (H'), Al e compactação do solo. Percebe-se a grande influência do $\mathrm{pH}$ sobre os teores de nutrientes do solo. De um modo geral, a disponibilidade desses elementos no solo é função do $\mathrm{pH}$, reduzindo à medida que o $\mathrm{pH}$ diminui, e estando disponível em maiores concentrações à medida que o pH atinge níveis próximos a neutralidade (COELHO; VERLENGIA, 1973).

A forte correlação negativa entre o pH e o $\mathrm{Al}$ indica a relação química existente entre essas variáveis, visto que em níveis baixos de $\mathrm{pH}$, ocorre maior solubilização do Al no solo, podendo trazer consequências nocivas às comunidades de plantas e biota do solo (MELLO et al., 1983). No presente estudo, essa estreita relação entre estas variáveis tornou-se claramente perceptível.

As demais variáveis mostram-se fracas na composição dos seus respectivos fatores. Observa-se que, embora a densidade de indivíduos (Ni), esteja associada ao quarto componente juntamente com a matéria orgânica, essa variável apresenta considerável correlação com as variáveis do primeiro componente, especialmente a área basal, o que é esperado, visto que quanto maior o número de indivíduos, maior tende a ser a área basal.

Sendo assim, é possível afirmar que de todas as variáveis utilizadas no agrupamento das subunidades, o pH é a mais determinante, influenciando de maneira geral a disponibilidade de nutrientes e demais aspectos da vegetação.

Tais resultados corroboram com Coelho e Verlengia (1973), que afirmam que o pH é possivelmente a única variável que quando considerada isoladamente dá mais informações sobre o solo. O Ca por sua vez, por possuir maior valência e íons de tamanho maior quando hidratados, é adsorvido com maior energia de ligação às cargas do solo, conforme a série liotrópica, influenciando a disponibilidade do Mg, P e K (MELLO et al., 1983). Além dos aspectos químicos influenciados pelo $\mathrm{Ca}$, esse é o nutriente que tem maior efeito agregante no solo, favorecendo a permeabilidade e infiltração de água, afetando o desenvolvimento do sistema radicular das plantas.

No tocante à vegetação, obteve-se uma relação direta entre a Área Basal (G) e o pH, embora ambos tenham sido negativamente correlacionados com o fator 1 (Tabela 2). Isso indica que nas áreas que apresentaram maior $\mathrm{pH}$, houve também maiores valores de área basal. Entretanto, observa-se que houve relação inversa entre o

FLORESTA, Curitiba, PR, v. 46, n. 2, p. 145 - 154, abr. / jun. 2016

Rodrigues, A. L. et al.

ISSN eletrônico 1982-4688

DOI: $10.5380 /$ rf.v46i2.36219 
pH e variáveis do solo a ele relacionadas, com o Índice de Diversidade de Shannon (H'), indicando o aumento na diversidade florística à medida que o $\mathrm{pH}$ e disponibilidade de nutrientes diminui.

A figura 3 representa a relação direta existente entre o pH e a Área Basal e a relação inversa dessas variáveis com a Diversidade, representando a evolução desses parâmetros ao longo do gradiente edáfico identificado nas transecções B e C.
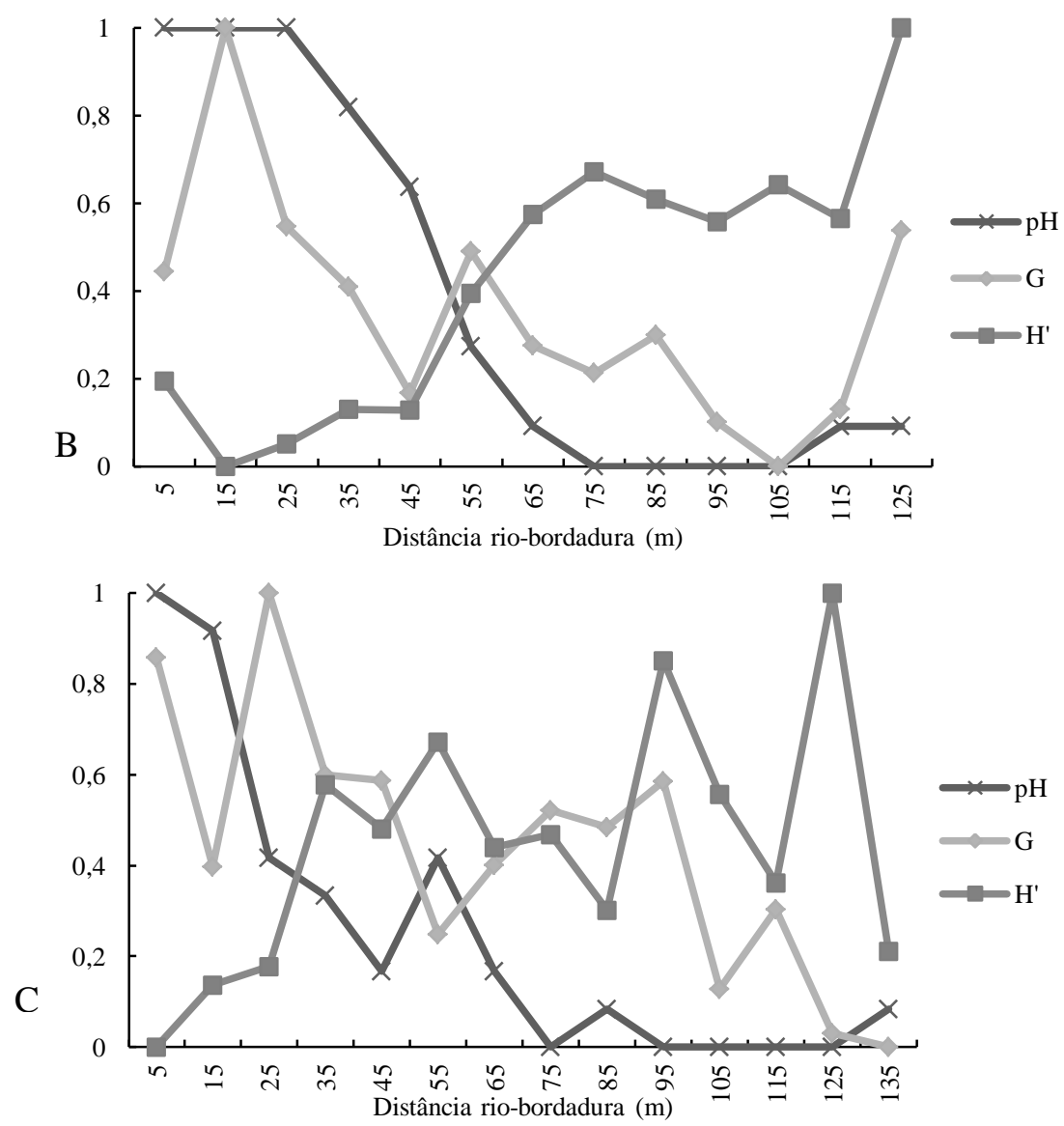

Figura 3. Comportamento das variáveis pH, Área Basal (G) e Índice de Diversidade de Shannon (H'), ao longo de um gradiente edáfico (transecções B e C) em um fragmento de Floresta Ombrófila Mista Aluvial, Guarapuava, PR (Por motivo de comparação em uma mesma escala, variáveis com diferentes unidades tiveram seus valores relativizados de $0-1$ ).

Figure 3. Tendency of variables $\mathrm{pH}$, Shannon Diversity Index and Basal Area along an edaphic gradient (transections B and C) in an Alluvial Araucaria Forest, Guarapuava, PR (Aiming the comparison on a same scale, variables with different units had their values relativized 0-1).

Com base nas relações observadas na figura 3 , infere-se que, embora valores baixos de $\mathrm{pH}$, como aqueles observados nas subunidades finais das transecções B e C, sejam danosos ao desenvolvimento das plantas, seja por reduzir a disponibilidade de nutrientes ou por aumentar a solubilidade de elementos tóxicos, esse não parece ser o fator de maior limitação ao aumento da diversidade da floresta. Neste caso, o possível nível do lençol freático, associado à rugosidade da superfície do terreno responsável pela formação de pequenas bacias de inundação, características estas presentes nas parcelas iniciais das transecções B e C, pode ser o fator mais limitante ao desenvolvimento da comunidade arbórea na área de estudo.

A influência das condições de drenagem do solo sobre a vegetação também pode ser constatada na transecção A. A área amostrada por esta transecção apresenta solos mais profundos e melhores condições de drenagem, e nesta mesma área foram obtidos os maiores valores de Índice de Diversidade de Shannon, mesmo apesar da condição de alta acidez e baixos teores de nutrientes. 
Já a relação inversa observada entre a Área Basal e o pH está associada basicamente aos altos valores de área basal obtidos pela espécie hidrófila Sebastiania commersoniana (Baill.) L.B. Sm. \& Downs nas parcelas iniciais das transecções B e C. Nessas subunidades esta espécie foi praticamente absoluta ocorrendo de forma agregada, com um grande número de indivíduos de pequenos diâmetros, resultando em elevados valores de área transversal. Por outro lado, na transecção A, que não apresentou solos hidromórficos, a participação de Sebastiania commersoniana foi reduzida ao longo de toda a transecção, dando lugar a um maior número de espécies, o que resultou nos maiores valores para o Índice de Shannon.

Constatações semelhantes foram feitas por Barddal et al. (2004), estudando um fragmento de Floresta Ombrófila Mista Aluvial em Araucária, PR. Esses autores observaram que nas áreas mais sujeitas às inundações e elevação do lençol freático, Sebastiania commersoniana foi dominante também em decorrência do alto número de indivíduos, embora com diâmetros pequenos. À medida que a condição hidromórfica do solo diminuía, outras espécies também tolerantes à hidromorfia, porém, de adaptação mais limitada, tomavam espaço na comunidade arbórea, promovendo o aumento da diversidade.

Conforme Curcio et al. (2007), as características dos solos aluviais, como os processos de transporte e deposição de materiais e oscilações do lençol freático, são importantes, e de maneira interativa, são responsáveis pela presença de determinada ocupação vegetacional, como ocorre na área de estudo. Estudos semelhantes, conduzidos por Medri et al. (2002) e Lobo e Joly (2000), discutem a frequência e duração da saturação hídrica do solo como um dos fatores determinantes à composição florística. Com base nestas afirmações, pode-se inferir que a vegetação presente ao longo das margens de rios, sobre solos sujeitos ao regime fluvial, ocorre de acordo com diferentes grupos funcionais, que refletem as adaptações das espécies em função da saturação hídrica dos solos.

\section{CONCLUSÕES}

- Os solos da área estudada apresentaram condições de elevada acidez, alta concentração de $\mathrm{Al}^{+3}$ e baixa saturação por bases, indicando locais de baixa fertilidade natural;

- A análise de agrupamentos indicou a existência de um gradiente edáfico nas áreas amostradas pelas transecções B e C, enquanto as subunidades de A apresentaram maior similaridade entre si;

- A análise de componentes principais destacou o pH, Ca e Al como as variáveis ambientais avaliadas de maior importância, sendo o pH um importante condicionante das demais características do solo e, consequentemente, da vegetação.

\section{REFERÊNCIAS}

ANGIOSPERM PHYLOGENY GROUP. An update of the Angiosperm Phylogeny Group classification for the orders and families of flowering plants: APG III. Botanical Journal of the Linnean Society, London, v. 161, n. 2, p. $105-121,2009$.

BARDDAL, M. L.; RODERJAN, C. V.; GALVÃO, F.; CURCIO, G. R. Caracterização florística e fitossociológica de um trecho sazonalmente inundável de floresta aluvial, em Araucária, PR. Ciência Florestal, v. 14 , n. 2, p. 37 - 50, 2004

BOETTINGER, J. L. Alluvium and alluvial soils. In: HILLEL, D. Encyclopedia of Soils in the Environment. Oxford: Elsevier, 2005. p. 45 - 49.

COElHO, F. S.; VERLENGIA, F. Fertilidade do solo. Campinas: Instituto Campineiro de Ensino Agrícola, 1973. 384 p.

CAMBI, M.; CERTINI, G.; NERI, F.; MARCHI, E. The impacto f heavy traffic on forest soils: a review. Forest Ecology and Management, v. 338, p. 124 - 138, 2015.

CURCIO, G. R.; GALVÃO, F.; BARDDAL, M. L.; DEDECEK, R. A. A floresta fluvial em dois compartimentos do rio Iguaçu, Paraná, Brasil. Floresta, v. 37, n. 2, p. 125 - 147, 2007.

EMPRESA BRASILEIRA DE PESQUISA AGROPECUÁRIA (EMBRAPA). Manual de métodos de análise de solo. Rio de Janeiro: EMBRAPA/SNLCS, 1997. 212 p.

HEINEMAN, K. D.; TURNER, B. L.; DALLING, J. W. Variation in wood nutrients along a tropical soil fertility gradient. New Phytologist, v. 210, n. 3, p. 1103 - 1110, 2016. 
JOHN, R.; DALlinG, J. W.; HARMS, K. E.; YAVITT, J. B.; STALLARD, R. F.; MIRABELLO, M.; HUBBELL, S. P.; VALENCIA, R.; NAVARRETE, H.; VALLEJO, M.; FOSTER, R. B. Soil nutrients influence spatial distributions of tropical tree species. Proceedings of the National Academy of Sciences, v. 104, n. 3, p. $864-869,2007$.

LOBO, P. C.; JOLY, C. A. Aspectos ecofisiológicos da vegetação de mata ciliar do sudoeste do Brasil. In: RODRIGUES, R. R.; LEITÃO FILHO, H. F.(Eds.) Matas ciliares: conservação e recuperação. 1. ed. São Paulo: Ed. Edusp, 2000. p. 143 - 158.

LOPES, L. C. M.; MARIANO-NETO, E.; AMORIN, A. M. Can soil types explain species distributions? Evaluating the woody understory component of a tropical forest in Brazil. Brazilian Journal of Botany, v. 39, n. 1, p. $251-259,2016$.

MEDRI, M. E.; BIANCHINI, E.; PIMENTA, J. A.; COLLI, S.; MULLER, C. Estudos sobre a tolerância ao alagamento em espécies arbóreas nativas da bacia do rio Tibagi. In: MEDRI, M. E.; BIANCHINI, E.; ShIBATTA, O. A.; PIMENTA, J. A. (eds.). A Bacia do Rio Tibagi. Londrina: edição dos Editores, 2002.

MELlO, F. A. F.; BRASIL SOBRINHO, M. O. C.; ARZOLLA, S.; SILVEIRA, R. I.; COBRA NETTO, A.; KIEHL, J. C. Fertilidade do solo. São Paulo: Nobel, 1983.400 p.

MICHAELIS, J.; PANNEK, A.; DIEKMANN, M. Soil pH limits of forest vascular plants determine range size and threat level. Journal of Vegetation Science, v. 27, n. 2, p. 315 - 322, 2016.

MONTAGNE, D.; CORNU, S.; LE FORESTIER, L.; COUSIN, I. Soil drainage as an active agent of recent soil evolution: A review. Pedosphere, v. 19, n. 1, p.1 - 13, 2009.

PALLARDY, E. G. Physiology of woody plants. 3 ed, San Diego: Academic Press, 2008. 377 p.

ROUSSEAU, G. X.; DEHEUVEL, O.; ARIAS, I. R.; SOMARRIBA, E. Indicating soil quality in cacao-based agroforestry systems and old-growth forests: The potential of soil macrofauna assemblage. Ecological Indicators, v. 23, n. 0, p. 535 - 543, 2012.

UNITED STATES DEPARTMENT OF AGRICULTURE - USDA. Soil survey manual. Washington, DC: Soil Survey Division Staff, 1993. 437 p.

VENANZI, R.; PICCHIO, R.; PIOVESAN, G. Silvicultural and logging impact on soil characteristics in Chestnut (Castanea sativa Mill.) Mediterranean coppice. Ecological engineering, v. 92, p. 82 - 89, 2016.

WU,C. C.; TSUI,C. C.; CHANG-FU HSEIH,C. F.; ASIO,V. B.; CHEN, Z. S. Mineral nutrient status of tree species in relation to environmental factors in the subtropical rain forest of Taiwan. Forest Ecology and Management, v. 239, n. 1 - 3, p. 81 - 91, 2007.

ZELLWEGER, F.; BRAUNISCH, V.; MORSDORF, F.; BALTENSWEILER, A.; ABEGG, M.; ROTH, T.; BUGMANN, H.; BOLLMAN, K. Disentangling the effects of climate, topography, soil and vegetation on standscale species richness in temperate forests. Forest Ecology and Management, v. 349, p. 36 - 44, 2015. 